\title{
Secuelas oftalmológicas secundarias a Síndrome de Stevens
} - Johnson

Ophthalmic sequelae due to Stevens - Johnson syndrome

\section{Sequelas oftalmológicas secundárias à Síndrome de Stevens -Johnson}

Virgilio Galvis, MD., Esp., PhD. *

Angélica Pedraza-Concha, MD. ${ }^{* *}$

Alejandro Tello, MD., Esp., PhD. *

Néstor I. Carreño, MD., Esp. ${ }^{* * *}$

Rubén D. Berrospi, MD., Esp. ***

Camilo A. Niño, MD., Esp. ${ }^{* * *}$
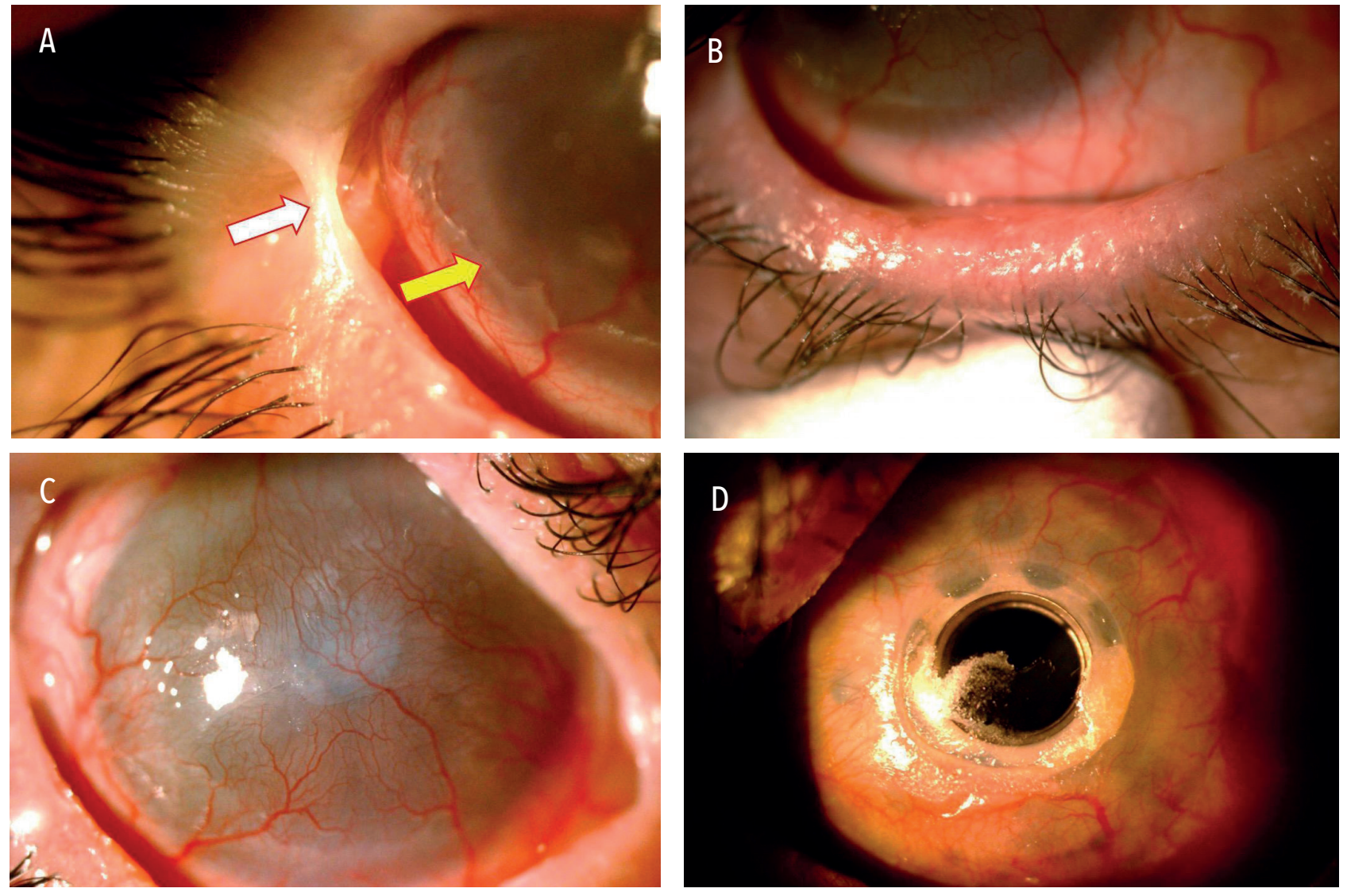

*Médico, Especialista en Oftalmología, Subespecialista en Facoemulsificación y Segmento Anterior, Subespecialista en Cirugía refractiva, Doctorado en Investigación, Cirugía y especialidades Médico-quirúrgicas, Doctorado en Ciencias de la Visión, Centro Oftalmológico Virgilio Galvis, Universidad Autónoma de Bucaramanga, Fundación Oftalmológica de Santander, Floridablanca, Santander, Colombia.

** Médico en Servicio Social Obligatorio, Asistente Editorial, Universidad Autónoma de Bucaramanga, Floridablanca, Santander, Colombia

***Médico, Especialista en Oftalmología. Centro oftalmológico Virgilio Galvis, Fundación Oftalmológica de Santander, Universidad Autónoma de Bucaramanga, Floridablanca, Santander, Colombia.

Correspondencia: Angélica Pedraza Concha, Calle 157 No. 14 - 55, Floridablanca, Santander, Colombia. E-mail: apedraza72@unab.edu.co Artículo recibido: 31 de septiembre de 2018 Artículo aceptado: 23 de noviembre de 2018 
Figura A. Simblefaron, es decir adherencia de los bordes de los dos párpados (flecha blanca) y queratinización del limbo esclero-corneal (flecha amarilla) en el ojo derecho. Figura B. Ojo derecho: irregularidad del borde del párpado inferior con obstrucción completa y queratinización de los puntos de drenaje de las Glándulas de Meibomio, como consecuencia de la inflamación crónica secundaria al Síndrome de Stevens - Johnson. Figura C. Ojo derecho: conjuntivalización completa por falla del limbo y pérdida del epitelio corneal en el ojo derecho de la paciente, llevando a una córnea totalmente opaca como secuela del ojo seco severo crónico secundario al síndrome de Stevens - Johnson. Figura D. Ojo izquierdo: queratoprótesis de Boston Tipo I in situ. Se aprecia el cilindro central que permite el paso de la luz al interior del ojo. Los agujeros que translucen a través del tejido se encuentran en la placa de titanio que sostiene fijo el cilindro óptico al tejido corneal de un donante, que se suturó a la córnea periférica de la paciente. Ese tejido corneal donante se encuentra completamente conjuntivalizado y opaco, pero el extremo del cilindro óptico, al ser de material sintético, mantiene la transparencia. Se evidencia queratinización de la superficie con acúmulo de queratina en la interfase entre el material sintético del cilindro y el tejido corneal.

Figure A. Symblepharon, i.e., adhesion from the edges of the two eyelids (white arrow) and keratinization of the sclerocorneal limbus (yellow arrow) in the right eye. Figure B. Right eye: irregularity from the edge of the lower eyelid with complete obstruction and keratinization of the excretory ducts of the Meibomian glands, due to chronicity of the inflammation in consequence to Stevens - Johnson syndrome. Figure C. Right eye: showing complete conjunctivalization due to limbus failure and loss of the corneal epithelium in the patient's right eye, leading to corneal haze as a sequel to chronic severe dry eye secondary to Stevens - Johnson syndrome. Figure D. Left eye: Boston type I keratoprosthesis in situ. As showed, the central cylinder allows light to enter through the eye. The holes seen through the tissue are on the titanium plate that holds the optical cylinder in place on the corneal tissue of a donor, sutured to the patient's peripheral cornea. This donor corneal tissue is completely conjunctivalized and hazy, but since the end of the optical cylinder is made of synthetic material, it remains transparent. Keratinization of the surface is evident, with an accumulation of keratin in the interface between the synthetic material of the cylinder and the corneal tissue.

Figura A. Simbléfaro, ou seja, aderência das bordas das pálpebras (seta branca) e queratinização do limbo esclerocorneano (seta amarela) no olho direito. Figura B. Olho direito: irregularidade da borda da pálpebra inferior com obstrução completa e queratinização dos pontos de drenagem das glândulas meibomianas, como consequência da inflamação crônica secundária à síndrome de Stevens - Johnson. Figura C. Olho direito: conjuntivalização completa devido a falha do limbo e perda do epitélio corneano no olho direto da paciente, ocasionando uma córnea completamente opaca como sequela do olho seco crônico grave secundário à síndrome de Stevens-Johnson. Figura D. Olho esquerdo: ceratoprótese de Boston Tipo I in situ. O cilindro central que permite a passagem da luzpara o olho é apreciado. Os orificios translúcidos através do tecido estão na placa de titânio que segura o cilindro óptico ao tecido corneano de um doador, o qual foi suturado à córnea periférica da paciente. Esse tecido corneano doado está completamente conjuntivalizado e opaco, mas o extremo do cilindro óptico, por ser feito de material sintético, mantém a transparência. É evidente a queratinização da superfície com acúmulo de queratina na interface entre o material sintético do cilindro e o tecido corneano.

Mujer de 75 años con secuelas oftálmicas crónicas secundarias a Síndrome de Stevens-Johnson (SSJ) padecido en 2005, posterior a la ingesta de fenitoína. El SSJ forma parte del espectro de reacciones farmacológicas adversas muco-cutáneas (1-3). La paciente presentó queratoconjuntivitis sicca severa relacionada con la inflamación crónica de la superficie ocular, queratinización de los ductos de la glándula lagrimal en el fondo de saco conjuntival superior e inflamación persistente del borde de los párpados que llevó finalmente a la pérdida de las glándulas de Meibomio. Secundariamente, debido a la grave alteración de la homeostasis de la superficie ocular, ocurriólapérdidadelas células madre del epitelio corneal en el limbo, distriquiasis, triquiasis, y simblefaron, en concordancia con las secuelas reportadas en la literatura (1-3) (Figuras A-C). Por la presencia de ojo seco grave y falla limbar con conjuntivalización secundaria de la córnea, en estos pacientes está contraindicada la realización de un trasplante de córnea. Una alternativa es la implantación de una córnea artificial, o queratoprótesis. A la paciente se le implantó una queratoprótesis Boston tipo 1 en el año 2007 en el ojo izquierdo (OI). Esta prótesis contiene un cilindro que tiene un reborde hecho de polimetilmetacrilato y un eje central de aproximadamente $3 \mathrm{~mm}$ de diámetro que 
se acopla atornillado a placa posterior (actualmente de titanio) atravesando un disco de córnea de un donante, que a su vez se sutura en la córnea del receptor, luego de resecar la porción central (Figura D) $(4,5)$. De esta manera, aunque se presente conjuntivalización y opacificación del tejido donante, el cilindro central sintético permanecerá translúcido. Como complicación se presentó extrusión del cilindro de la queratoprótesis en 2010, por lo cual fue retirada. Se realizó un reimplante de la queratoprótesis e implante de válvula Ahmed (para el control de la presión intraocular) en 2011. A pesar de ello, presentó un glaucoma secundario de difícil manejo, por lo que la visión con corrección en el OI es solo de 20/200, con un campo visual muy restringido. El ojo derecho (OD) no se ha intervenido quirúrgicamente. La agudeza visual en el OD es movimiento de manos que no mejora.

Recientemente se ha sugerido en la literatura el empleo temprano de medidas agresivas en la fase aguda, como el trasplante de membrana amniótica, lo que podría disminuir la severidad de las secuelas del SSJ (2,6-9).

El uso de queratoprótesis, aunque puede funcionar para mejorar la visión, aún se relaciona con importantes riesgos en este tipo de pacientes, siendo el glaucoma uno de los más frecuentes y la colagenolisis alrededor del cilindro de la prótesis, más probable en estos pacientes de enfermedades relacionadas con autoinmunidad, uno de los más graves $(5,10)$. El uso del anticuerpo monoclonal Infliximab, por vía intravenosa ante la presencia de colagenolisis, parece prevenir la progresión de la degradación del colágeno, pero se requieren estudios adicionales (11). En conclusión, aún existe mucho por investigar para ofrecer alternativas con seguridad a largo plazo en estos casos difíciles. Nuestra paciente ha preferido esperar por nuevos desarrollos más seguros y efectivos para optar por una alternativa quirúrgica en su $\mathrm{OD}$, pues ella considera que la visión que se ha logrado por el OI luego de múltiples procedimientos, no es satisfactoria.
[Galvis V, Pedraza-Concha A, Tello A, Carreño NI, Berrospi RD, Niño CA. Secuelas oftalmológicas secundarias a Síndrome de Stevens - Johnson. MedUNAB. 2018;21(2):8-11. doi:10.29375/01237047.3487]

[Galvis V, Pedraza-Concha A, Tello A, Carreño NI, Berrospi RD, Niño CA. Ophthalmic sequelae due to Stevens - Johnson syndrome. MedUNAB. 2018;21(2):8-11. doi:10.29375/01237047.3487]

[Galvis V, Pedraza-Concha A, Tello A, Carreño NI, Berrospi RD, Niño CA. Sequelas oftalmológicas secundárias à Síndrome de Stevens - Johnson. MedUNAB. 2018;21(2):8-11. doi:10.29375/01237047.3487]

\section{Conflicto de intereses}

Los autores declaran no tener conflictos de interés.

\section{Referencias}

1. Chang VS, Chodosh J, Papaliodis GN. Chronic ocular complications of Stevens-Johnson syndrome and toxic epidermal necrolysis: The role of systemic immunomodulatory therapy. Semin Ophthalmol. 2016;31(1-2):178-87. doi: 10.3109/08820538.2015.1114841

2. Jain R, Sharma N, Basu S, Iyer G, Ueta M, Sotozono $\mathrm{C}$, et al. Stevens-Johnson syndrome: The role of an ophthalmologist. Surv Ophthalmol. 2016;61(4):36999. doi: 10.1016/j.survophthal.2016.01.004

3. De Rojas V, Dart J, Saw V. The natural history of Stevens-Johnson syndrome: Patterns of chronic ocular disease and the role of systemic immunosuppressive therapy. Br J Ophthalmol. 2007;91(8):1048-53. doi: 10.1136/bjo.2006.109124

4. Chang HY, Luo ZK, Chodosh J, Dohlman CH, Colby KA. Primary implantation of type I Boston keratoprosthesis in nonautoimmune corneal dis- 
eases. Cornea. 2015;34(3):264-70. doi: 10.1097/ ICO.0000000000000357.

5. Sayegh RR, Ang LP, Foster CS, Dohlman CH. The Boston keratoprosthesis in Stevens-Johnson syndrome. Am J Ophthalmol. 2008;145(3):438-44. doi: 10.1016/j.ajo.2007.11.002. Epub 2008 Jan 22.

6. Schneider JA, Cohen PR. Stevens-Johnson Syndrome and Toxic Epidermal Necrolysis: A Concise Review with a Comprehensive Summary of Therapeutic Interventions Emphasizing Supportive Measures. Adv Ther. 2017;34(6):1235-1244. doi: 10.1007/s12325-017-0530-y

7. Galvis V, Tello A, Laverde C, Santaella G, Gómez AJ, Diaz AL. Amniotic membrane transplantation in Stevens-Johnson syndrome. Surv Ophthalmol. 2017;62(2):248-249. doi: 10.1016/j.survophthal.2016.10.001

8. Gregory DG. New Grading System and Treatment Guidelines for the Acute OcularManifestations of Stevens-Johnson Syndrome. Ophthalmology. 2016;123(8):1653-58. doi: 10.1016/j. ophtha.2016.04.041
9. Sharma N, Thenarasun SA, Kaur M, Pushker N, Khanna N, Agarwal T, Vajpayee RB. Adjuvant Role of Amniotic Membrane Transplantation in Acute Ocular Stevens-Johnson Syndrome: A Randomized Control Trial. Ophthalmology. 2016;123(3):484-91

10. Robert MC, Dohlman CH. A review of corneal melting after Boston Keratoprosthesis. Semin Ophthalmol. 2014;29(5-6): 349-57. doi: 10.1016/j.ophtha.2015.10.027

11. Robert MC, Črnej A, Shen LQ, Papaliodis GN, Dana R, Foster CS, Chodosh J, Dohlman CH. Infliximab after Boston Keratoprosthesis in Stevens-Johnson Syndrome: An Update. Ocul Immunol Inflamm. 2017;25(3):413-417. doi: $10.3109 / 09273948.2016 .1145237$ 